\title{
Higher-Dose DHA Supplementation Modulates Immune Responses in Pregnancy and Is Associated with Decreased Preterm Birth
}

\author{
Christina J. Valentine ${ }^{1, *}$, Aiman Q. Khan ${ }^{2}$, Alexandra R. Brown ${ }^{3}$, Scott A. Sands ${ }^{4}$, Emily A. Defranco ${ }^{5}$, \\ Byron J. Gajewski ${ }^{3}$, Susan E. Carlson ${ }^{4}$ (D), Kristina M. Reber ${ }^{6}$ and Lynette K. Rogers ${ }^{2,7}$ (D)
}

\section{check for} updates

Citation: Valentine, C.J.; Khan, A.Q.; Brown, A.R.; Sands, S.A.; Defranco,

E.A.; Gajewski, B.J.; Carlson, S.E.;

Reber, K.M.; Rogers, L.K.

Higher-Dose DHA Supplementation

Modulates Immune Responses in

Pregnancy and Is Associated with Decreased Preterm Birth. Nutrients 2021, 13, 4248. https://doi.org/ $10.3390 /$ nu13124248

Academic Editor: Sébastien Bailly

Received: 25 October 2021

Accepted: 24 November 2021

Published: 26 November 2021

Publisher's Note: MDPI stays neutral with regard to jurisdictional claims in published maps and institutional affiliations.

Copyright: (c) 2021 by the authors Licensee MDPI, Basel, Switzerland. This article is an open access article distributed under the terms and conditions of the Creative Commons Attribution (CC BY) license (https:/ / creativecommons.org/licenses/by/ $4.0 /)$.
1 Department of Pediatrics, University of Arizona, Tucson, AZ 85721, USA

2 Center for Perinatal Research, The Abigail Wexner Research Institute at Nationwide Children's Hospital, Columbus, OH 43215, USA; Aiman.Khan@Nationwidechildrens.org (A.Q.K.); Lynette.Rogers@Nationwidechildrens.org (L.K.R.)

3 Department of Biostatistics \& Data Science, University of Kansas Medical Center, Kansas City, KS 66160, USA abrown8@kumc.edu (A.R.B.); bgajewski@kumc.edu (B.J.G.)

4 Department of Dietetics and Nutrition, University of Kansas Medical Center, Kansas City, KS 66160, USA; ssands@kumc.edu (S.A.S.); scarlson@kumc.edu (S.E.C.)

5 Department of Obstetrics and Gynecology, University of Cincinnati College of Medicine, Cincinnati, OH 45267, USA; defranee@ucmail.uc.edu

6 Department of Pediatrics, Baylor College of Medicine, Houston, TX 77030, USA; kmreber@texaschildrens.org

7 Department of Pediatrics, Ohio State University, Columbus, OH 43210, USA

* Correspondence: Valentine2@email.arizona.edu; Tel.: +1-520-626-6627

\begin{abstract}
Pregnancy and parturition involve extensive changes in the maternal immune system. In our randomized, multi-site, double-blind superiority trial using a Bayesian adaptive design, we demonstrated that $1000 \mathrm{mg}$ /day of docosahexaenoic acid (DHA) was superior to $200 \mathrm{mg} /$ day in preventing both early preterm birth (less than 34 weeks' gestation) and preterm birth (less than 37 weeks' gestation). The goal of this secondary study is to compare the effects of $1000 \mathrm{mg}$ /day versus $200 \mathrm{mg}$ /day on maternal inflammation, a possible mechanism by which DHA may prevent preterm birth. Maternal blood samples were collected at enrollment (12-20 weeks' gestation) and at delivery. Red blood cell DHA levels were measured by gas chromatography, and plasma concentrations of sRAGE, IL-6, IL-1 $\beta$, TNF $\alpha$, and INF $\gamma$ were measured by ELISA. Data were analyzed for associations with the DHA dose, gestational age at birth, and preterm birth ( $<37$ weeks). Higher baseline and lower delivery levels of maternal sRAGE were associated with a greater probability of longer gestation and delivery at term gestation. Higher-dose DHA supplementation increased the probability of a smaller decrease in delivery sRAGE levels. Higher IL-6 concentrations at delivery were associated with the probability of delivering after 37 weeks, and higher-dose DHA supplementation increased the probability of greater increases in IL-6 concentrations between enrollment and delivery. These data provide a proposed mechanistic explanation of how a higher dose of DHA during pregnancy provides immunomodulatory regulation in the initiation of parturition by influencing sRAGE and IL-6 levels, which may explain its ability to reduce the risk of preterm birth.
\end{abstract}

Keywords: preterm birth; pregnancy; DHA; sRAGE; IL-6; Bayesian adaptive design

\section{Introduction}

Parturition is associated with leukocyte infiltration and the release of cytokines to initiate labor [1,2]. The physiological events that surround preterm parturition remain elusive but previous data support the finding that maternal inflammation is a primary contributor to preterm birth. Given the anti-inflammatory properties of docosahexaenoic acid (DHA), it has been investigated as a plausible therapeutic to prolong gestation by preventing preterm parturition $[3,4]$. In our previous trial comparing maternal supplementation of $200 \mathrm{mg}$ versus $1000 \mathrm{mg}$ of DHA per day, $200 \mathrm{mg}$ was found to have little to no 
effect on maternal, infant, or breast milk inflammatory markers, whereas the women ingesting $1000 \mathrm{mg}$ per day had significant decreases in plasma and breast milk inflammatory cytokine expression [5].

DHA is a metabolically active fatty acid that has been extensively studied in the context of nutrition, neurodevelopment, and immunology [3,6-10]. The incorporation of DHA into membrane phospholipids affects lipid raft formation, which further affects receptor-mediated signaling and changes in membrane fluidity $[3,7,10]$. Investigations have demonstrated that, unlike other omega-3 fatty acids, DHA regulates interactions between cell surface ligands and receptors, resulting in attenuated inflammation [11-15].

Preterm birth is associated with both low maternal blood levels of DHA and low DHA dietary intake [16,17]. Maternal DHA supplementation has demonstrated efficacy in preventing preterm birth, but the optimal dose required to achieve a protective effect has not been clearly defined and the mechanism of action has not been identified [4]. Experts recommend ingesting between $200 \mathrm{mg}$ and $1000 \mathrm{mg}$ of DHA each day during pregnancy [18], and prenatal vitamin supplements typically provide DHA, but most contain $200 \mathrm{mg}$ or less. To address the need for evidence-based data on DHA dosing, we hypothesized that $1000 \mathrm{mg}$ of DHA per day would be superior to $200 \mathrm{mg}$ in preventing preterm birth [19]. Our randomized, multi-site, double-blind superiority trial using a Bayesian adaptive design demonstrated that the higher dose of DHA was superior to the lower dose in preventing both early preterm birth (less than 34 weeks' gestation) and preterm birth (less than 37 weeks' gestation) with participants with low baseline DHA levels at enrollment benefiting most from the higher-dose supplement [19].

Given the important role of inflammation in the preterm parturition cascade, this study tested a secondary hypothesis in this Phase 3 clinical trial: that supplementation with $1000 \mathrm{mg}$ per day of DHA would be superior to $200 \mathrm{mg}$ per day in regulating inflammatory responses and would provide a mechanism by which DHA prevents preterm birth. Several markers have been identified as indicative of inflammation in pregnancy [20-22] and some of the most significant are the focus of this investigation: the Receptor for Advanced Glycation End Products (specifically, soluble and extracellular forms, sRAGE), Interleukin (IL)-6, IL-1 $\beta$, Tumor Necrosis Factor alpha (TNF $\alpha$ ) and Interferon gamma (IFN $\gamma$ ). Data were analyzed for associations with the DHA dose, gestational age at birth, and preterm birth ( $<37$ weeks).

\section{Materials and Methods}

\subsection{Study Design}

The study design and enrollment details of the parent study have been previously published [19]. Women were recruited from three large academic medical centers: the University of Kansas, Ohio State University, and the University of Cincinnati. The study was approved by the University of Kansas Medical Center IRB which granted approval under a central IRB with reliance by the other institutions (STUDY00003455).

Briefly, pregnant women were randomly assigned to take 2 capsules of algal oil daily (totaling $800 \mathrm{mg}$ of DHA) or soybean and corn oil ( $0 \mathrm{mg}$ of DHA) beginning between 12 and 20 weeks of gestation. Both groups received a commercially available prenatal supplement containing $200 \mathrm{mg}$ of DHA. Therefore, the experimental group received $1000 \mathrm{mg}$ of DHA per day and the control group received $200 \mathrm{mg}$ of DHA per day. The final enrollment for the parent study included 1100 randomized participants; 492 women in the $200 \mathrm{mg}$ group and 540 in the $1000 \mathrm{mg}$ group (details are provided in Figure 1). DHA levels were measured and reported in the original publication using standard fatty acid extraction and gas chromatography measurements $[17,19]$. The immune markers, sRAGE and cytokines, were measured in participants that provided both enrollment and delivery samples for testing. The final numbers analyzed for this study were 902 individuals; 437 who received $200 \mathrm{mg}$ /day and 465 who received $1000 \mathrm{mg} /$ day. 


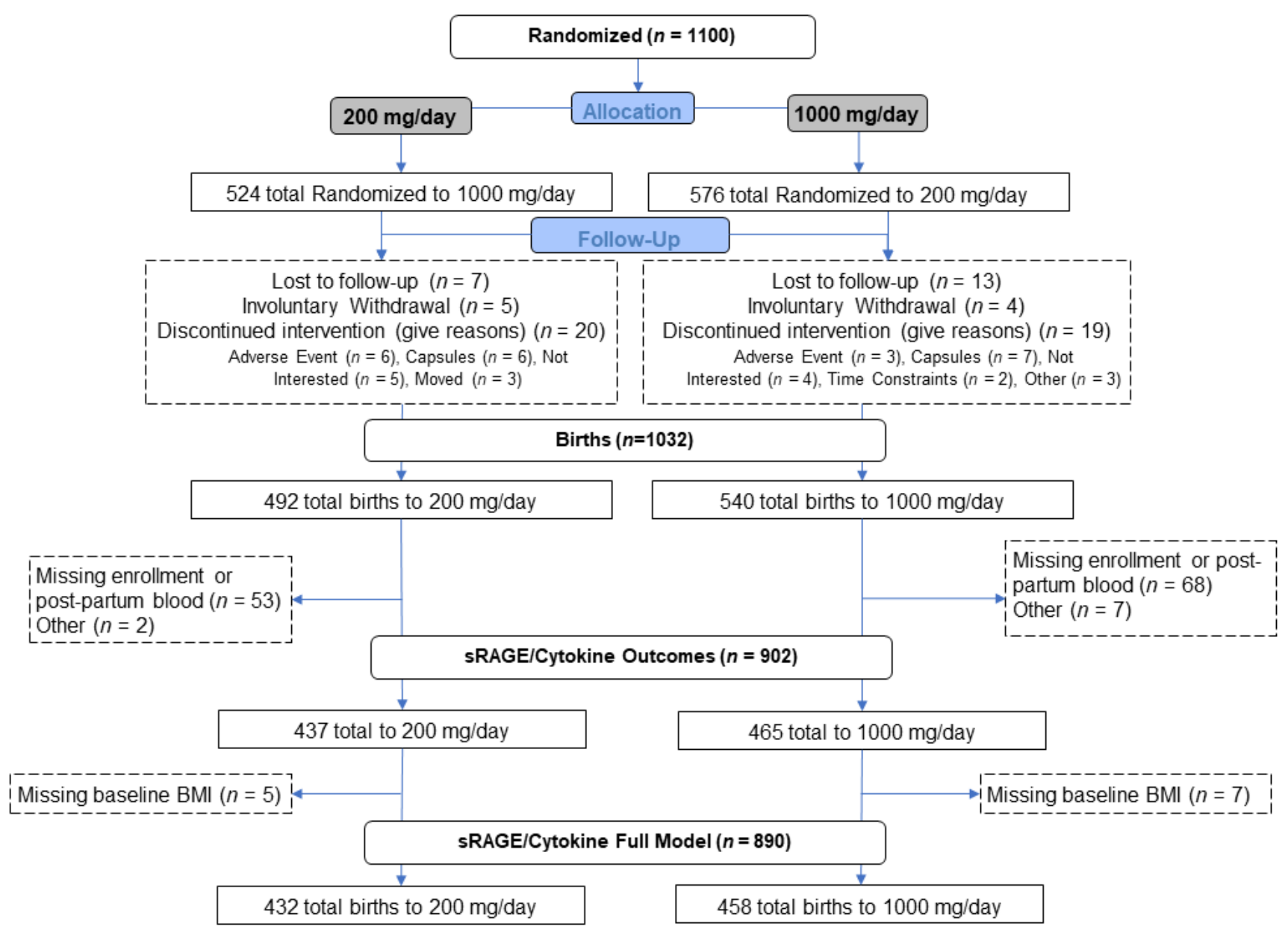

Figure 1. Study Design and Enrollment.

\subsection{Blood Collection}

Maternal blood samples were collected at enrollment and delivery hospitalization as previously described [19]. All samples were stored at $-80^{\circ} \mathrm{C}$ for the measurement of sRAGE and inflammatory cytokines.

\subsection{ELISA}

Analyses were performed on participants for whom both enrollment and delivery samples were available ( $n=437,200 \mathrm{mg}$ per day; $n=465,1000 \mathrm{mg}$ /day) (Figure 1). sRAGE was measured using an ELISA-based format (MesoScale Diagnostics, Rockville, MD, USA) according to the manufacturer's protocols and was analyzed independently. Cytokines, specifically IL-6, IL-1 $\beta, \mathrm{TNF} \alpha$, and IFN $\gamma$, were measured on plasma samples using a similar multi-plex ELISA platform.

\subsection{Statistical Analyses}

Normal Bayesian models were used to assess the effect of the sRAGE and cytokine levels of the treatment group at enrollment or delivery on maternal serum DHA sRAGE and cytokine concentrations. Normal Bayesian models also quantified the effect of the sRAGE and cytokine levels at enrollment and delivery on the outcome of gestational age at birth in weeks while accounting for the confounding variables (treatment group, maternal race and ethnicity, BMI group, history of preeclampsia, DHA at enrollment, and smoking history (before or during pregnancy)). Similarly, binomial Bayesian models were fit for the dichotomous outcome of preterm birth ( $<37$ weeks' gestation, yes $/$ no). Data are reported as posterior means and Bayesian credible intervals with posterior probabilities. The findings 
can be interpreted as the probability that DHA supplementation and the marker of interest are associated.

We utilized OpenBUGS version 3.2.3 rev 1012 for all Bayesian analyses (open access software developed by OpenBUGS Foundation; http:openbugs.net/w/OpenBUGS_3_2 3.Action=AttachFile\&do=get\&target=OpenBUGS-3.2.3.tar.gz). All analyses were fitted using 10,000 burn-in draws of Markov chain Monte Carlo, followed by 40,000 draws for inference. All prior distributions were non-informative.

\section{Results}

sRAGE and cytokine measurements were performed on all participants with available enrollment and delivery maternal blood samples. The parent study had 1032 births for which sRAGE and cytokine measurements could have been collected and analyzed. Overall, $<0.01 \%(4 / 1032)$ were missing baseline blood samples while $11.3 \%(117 / 1032)$ were missing delivery blood samples. A total of $11.7 \%(121 / 1032)$ were unable to have their sRAGE and cytokine data analyzed due to missing either a baseline or delivery blood draw. There were also $0.9 \%(9 / 1032)$ with samples unusable for processing and analysis, detailed in Figure 1. For infants born prematurely, prior to 37.0 weeks' gestation, $26.3 \%(31 / 118)$ were missing sRAGE and cytokine data due to missing or unusable blood samples while 10.8\% (99/914) of term deliveries were missing sRAGE and cytokine data. A descriptive summary of maternal sRAGE and the cytokine concentrations as well as pregnancy characteristics are included in Table 1.

Table 1. Descriptive Summary of Variables.

\begin{tabular}{|c|c|c|c|}
\hline & $\begin{array}{c}200 \mathrm{mg} / \mathrm{day} \\
n=437(47.6 \%)\end{array}$ & $\begin{array}{c}1000 \mathrm{mg} / \text { day } \\
n=465(52.4 \%)\end{array}$ & $\begin{array}{c}\text { Total } \\
n=902\end{array}$ \\
\hline \multicolumn{4}{|l|}{ sRAGE [pg/mL], mean (SD) } \\
\hline Enrollment & $564.4(286.4)$ & $520.6(279.4)$ & $541.8(283.5)$ \\
\hline Delivery & $467.7(277.3)$ & $443.1(381.4)$ & $455.0(335.1)$ \\
\hline \multicolumn{4}{|l|}{ IL 6 [pg/mL], mean (SD) } \\
\hline Enrollment & $0.9(1.0)$ & $1.3(6.1)$ & $1.1(4.4)$ \\
\hline Delivery & $4.5(7.5)$ & $7.7(26.0)$ & $6.1(19.4)$ \\
\hline \multicolumn{4}{|l|}{ IL $1 \beta[\mathrm{pg} / \mathrm{mL}]$, mean (SD) } \\
\hline Enrollment & $0.1(0.2)$ & $0.1(0.2)$ & $0.1(0.2)$ \\
\hline Delivery & $0.2(0.8)$ & $0.2(1.0)$ & $0.2(0.9)$ \\
\hline \multicolumn{4}{|l|}{$\mathrm{TNF} \alpha[\mathrm{pg} / \mathrm{mL}]$, mean $(\mathrm{SD})$} \\
\hline Enrollment & $1.7(0.7)$ & $1.9(2.1)$ & $1.8(1.6)$ \\
\hline Delivery & $2.1(1.0)$ & $2.1(1.0)$ & $2.1(1.0)$ \\
\hline \multicolumn{4}{|l|}{$\mathrm{INF} \gamma[\mathrm{pg} / \mathrm{mL}]$, mean $(\mathrm{SD})$} \\
\hline Enrollment & $6.4(30.8)$ & $5.1(13.5)$ & $5.7(23.5)$ \\
\hline Delivery & $5.1(22.7)$ & $4.4(8.9)$ & $4.7(17.0)$ \\
\hline DHA in RBC fatty acids [\%], mean (SD) & $6.5(1.8)$ & $6.4(1.8)$ & $6.5(1.8)$ \\
\hline Smoker (before or during pregnancy), yes $n(\%)$ & $105(24.0)$ & $112(24.1)$ & $217(24.1)$ \\
\hline \multicolumn{4}{|l|}{ Race, $n(\%)$} \\
\hline Non-Hispanic Black & $104(23.8)$ & $89(19.1)$ & $193(21.4)$ \\
\hline Other & $333(76.2)$ & $376(80.9)$ & $709(78.6)$ \\
\hline $\begin{array}{c}\text { History of Preeclampsia, } \\
\text { yes } n(\%)\end{array}$ & $33(7.6)$ & $30(6.5)$ & $63(7.0)$ \\
\hline BMI Group, $n(\%)$ & $n=432$ & $n=458$ & $n=890$ \\
\hline Obese & $138(31.9)$ & $159(34.7)$ & $297(33.4)$ \\
\hline Other $(\mathrm{BMI}<30)$ & $294(68.1)$ & $299(65.3)$ & $593(66.6)$ \\
\hline
\end{tabular}

Differences in the probability of a higher dose of DHA (1000 mg per day) to prevent preterm birth compared to a lower dose (200 $\mathrm{mg}$ per day) were noted in the parent trial between women with high ( $>6 \%$ of RBC total fatty acids) baseline DHA levels versus low baseline DHA ( $<6 \%$ of RBC total fatty acids) levels. As previously reported, $54 / 492$ (11\%) births occurred at $<37$ weeks in the $200 \mathrm{mg}$ /day group compared to $44 / 540(8.2 \%)$ in the $1000 \mathrm{mg} /$ day group, with a 0.95 posterior probability that $1000 \mathrm{mg}$ was better than 
$200 \mathrm{mg}$ [19]. Because of this finding, the baseline percent of DHA in red blood cells was included as a confounding variable. Other variables included in the analyses were smoking history (before or during pregnancy), maternal race and ethnicity (non-Hispanic Black versus other race and ethnicity), history of preeclampsia, and enrollment BMI ( $>30$ versus $\leq 30 \mathrm{~kg} / \mathrm{m}^{2}$ ). Twelve participants ( 5 at $200 \mathrm{mg} /$ day and 7 at $1000 \mathrm{mg} /$ day) were removed from the final models because data on baseline BMI were missing. The primary outcomes were gestational age at birth in weeks and preterm birth prior to 37 weeks of gestation.

As found in the parent study, treatment with $1000 \mathrm{mg}$ per day demonstrated a significant posterior probability $(\mathrm{pp}=0.99)$ of having a greater gestational age at birth compared to treatment with $200 \mathrm{mg}$ /day (Table 2). sRAGE concentrations were associated with gestational age at birth after adjusting for group and other covariates in the full model. Mothers with a higher baseline sRAGE concentration had a significantly longer gestation ( $\mathrm{pp}=0.99)$. Conversely, higher delivery sRAGE levels were predictive of an earlier gestational age at birth $(\mathrm{pp}=0.00)$. Race, pre-pregnancy BMI, history of preeclampsia, DHA at enrollment, and smoking history were found to be significant variables and were included in the final models. The association between sRAGE, DHA, pregnancy characteristics, and gestational age at birth are summarized in Table 2.

Table 2. Posterior means (Bayesian credible interval) and Bayesian posterior probability for sRAGE concentrations and the continuous variable (gestation age at birth) or the binary variable (preterm birth). The means are slopes for gestation age at birth and log-odds ratios for preterm birth.

Posterior Mean

(95\% Bayesian Credible Interval)

Bayesian Posterior Probability

\begin{tabular}{|c|c|c|}
\hline \multicolumn{3}{|l|}{ Gestational age at birth } \\
\hline $\begin{array}{c}\text { Treatment } \\
1000 \text { vs. } 200 \text { mg per day }\end{array}$ & $0.23(0.03,0.42)$ & 0.99 \\
\hline Enrollment sRAGE [pg/mL] & $0.0006(0.0002,0.0011)$ & 0.996 \\
\hline $\begin{array}{l}\text { Delivery sRAGE }[\mathrm{pg} / \mathrm{mL}] \\
\text { Significant variables }\end{array}$ & $-0.0008(-0.0012,-0.0004)$ & 0.00 \\
\hline $\begin{array}{c}\frac{\text { Maternal Race }}{\text { (non-Hispanic Black vs. other) }} \\
\text { (n) }\end{array}$ & $-0.44(-0.70,-0.19)$ & 0.0003 \\
\hline $\begin{array}{l}\text { Pre-pregnancy BMI } \\
\text { (obese vs. other) }\end{array}$ & $-0.50(-0.73,-0.27)$ & 0.00 \\
\hline $\begin{array}{l}\text { History of preeclampsia } \\
\text { (yes vs. no) }\end{array}$ & $-1.17(-1.56,-0.78)$ & 0.00 \\
\hline DHA at Enrollment [\%] & $0.08(0.02,0.13)$ & 0.996 \\
\hline $\begin{array}{l}\text { Smoker (before or during } \\
\text { pregnancy, yes vs. no) }\end{array}$ & $-0.21(-0.44,0.03)$ & 0.04 \\
\hline \multicolumn{3}{|l|}{ *;\# Preterm birth (<37 weeks) } \\
\hline $\begin{array}{c}\text { Treatment, } \\
1000 \text { vs. } 200 \text { mg per day }\end{array}$ & $0.59(0.33,0.96)$ & 0.98 \\
\hline Enrollment sRAGE [pg/mL] & $0.999(0.988,1.0)$ & 0.92 \\
\hline $\begin{array}{l}\text { Delivery sRAGE }[\mathrm{pg} / \mathrm{mL}] \\
\text { Significant variables }\end{array}$ & $1.001(1.0,1.002)$ & 0.002 \\
\hline $\begin{array}{c}\text { Maternal Race (non-Hispanic Black vs. } \\
\text { other) }\end{array}$ & $1.77(0.95,3.03)$ & 0.04 \\
\hline $\begin{array}{l}\text { Pre-pregnancy BMI } \\
\text { (obese vs. other) }\end{array}$ & $1.60(0.88,2.71)$ & 0.07 \\
\hline $\begin{array}{l}\text { History of preeclampsia } \\
\text { (yes vs. no) }\end{array}$ & $4.15(1.91,7.64)$ & 0.0003 \\
\hline DHA at Enrollment [\%] & $0.84(0.70,0.99)$ & 0.98 \\
\hline $\begin{array}{l}\text { Smoker (before or during } \\
\text { pregnancy, yes vs. no) }\end{array}$ & $1.40(0.75,2.34)$ & 0.16 \\
\hline
\end{tabular}

At least 5000 burn-in and 40,000 Markov chain draws were performed. DHA, \% total fatty acids; sRAGE pg/mL. * Modeling the probability of experiencing a preterm (<37 week) birth. \# Mean (SD) gestation age at birth for all samples analyzed, $38.8(1.6)$ weeks and \% preterm birth (9.6\%). 
Additional analyses using preterm birth ( $<37$ weeks, yes vs. no) as a binary outcome revealed similar findings (Table 2). As baseline sRAGE levels decreased, the probability of experiencing a preterm birth increased $(\mathrm{pp}=0.92)$. Moreover, lower delivery sRAGE levels are associated with a decrease in the odds of preterm birth $(\mathrm{pp}=0.002)$. All defined variables were included in the model.

The effects of the cytokines IL- 6 , IL- $1 \beta, \mathrm{TNF} \alpha$, and IFN $\gamma$ on gestational age at birth and preterm birth were analyzed individually, while adjusting for the covariates mentioned earlier (Table 3). Higher concentrations of TNF $\alpha$ and INF $\gamma$ at delivery were associated with an earlier gestational age at birth ( $p p=0.07$ and $p p=0.06$, respectively). No other significant associations between cytokines and gestational age at birth were found. In the binary analyses of preterm birth, higher levels of both enrollment and delivery IL-6 and lower enrollment levels of TNF $\alpha$ were associated with an increased probability of experiencing a birth at less than 37 weeks ( $\mathrm{pp}=0.87,0.85$, and $\mathrm{pp}=0.03$, respectively).

Table 3. Posterior means (Bayesian credible interval) and Bayesian posterior probability for cytokine concentrations and the continuous variable (gestation age at birth) or the binary variable (preterm birth). The means are slopes for gestation age at birth and log-odds ratios for preterm birth. For brevity, the maternal confounder parameter estimates are not shown.

\begin{tabular}{|c|c|c|}
\hline & $\begin{array}{c}\text { Posterior Mean } \\
\text { (95\% Bayesian Credible Interval) }\end{array}$ & Bayesian Posterior Probability \\
\hline \multicolumn{3}{|l|}{ Gestational age at birth } \\
\hline Enrollment IL-6 [pg/mL] & $0.003(-0.022,0.028)$ & 0.58 \\
\hline Delivery IL-6 [pg/mL] & $-0.0005(-0.0063,0.0055)$ & 0.44 \\
\hline Enrollment IL-1 $\beta$ [pg/mL] & $-0.18(-0.61,0.25)$ & 0.20 \\
\hline Delivery IL-1 $\beta$ [pg/mL] & $-0.03(-0.14,0.07)$ & 0.26 \\
\hline Enrollment TNF $\alpha$ [pg/mL] & $0.02(-0.04,0.09)$ & 0.76 \\
\hline Delivery TNF $\alpha[\mathrm{pg} / \mathrm{mL}]$ & $-0.08(-0.19,0.02)$ & 0.07 \\
\hline Enrollment INF $\gamma[\mathrm{pg} / \mathrm{mL}]$ & $-0.001(-0.005,0.003)$ & 0.27 \\
\hline Delivery INF $\gamma[\mathrm{pg} / \mathrm{mL}]$ & $-0.005(-0.010,0.001)$ & 0.06 \\
\hline \multicolumn{3}{|l|}{$\begin{array}{l}\text { * Preterm birth } \\
\text { (<37 weeks) }\end{array}$} \\
\hline Enrollment IL-6 [pg/mL] & $0.89(0.67,1.04)$ & 0.87 \\
\hline Delivery IL-6 [pg/mL] & $0.99(0.95,1.01)$ & 0.85 \\
\hline Enrollment IL-1 $\beta$ [pg/mL] & $1.53(0.56,3.00)$ & 0.20 \\
\hline Delivery IL-1 $\beta$ [pg/mL] & $0.91(0.60,1.16)$ & 0.73 \\
\hline Enrollment TNF $\alpha$ [pg/mL] & $0.73(0.45,1.04)$ & 0.95 \\
\hline Delivery TNF $\alpha[\mathrm{pg} / \mathrm{mL}]$ & $1.33(1.00,1.74)$ & 0.03 \\
\hline Enrollment INF $\gamma[\mathrm{pg} / \mathrm{mL}]$ & $0.99(0.95,1.01)$ & 0.83 \\
\hline Delivery INF $\gamma[\mathrm{pg} / \mathrm{mL}]$ & $0.996(0.972,1.010)$ & 0.62 \\
\hline
\end{tabular}

At least 5000 burn-in and 40,000 Markov chain draws were performed. All models included treatment, race, BMI group, history of preeclampsia, DHA at enrollment, and smoking history. The estimates were similar, and conclusions did not change from the sRAGE analysis above. ${ }^{*}$ Modeling the probability of experiencing a preterm $(<37$ week) birth.

The relative changes (delivery concentrations minus enrollment concentrations) in sRAGE, IL-6, IL-1 $\beta, \mathrm{TNF} \alpha$, or IFN $\gamma$ were analyzed with the treatment group alone as a predictor (Table 4). A smaller decrease in sRAGE and a greater increase in IL-6 (delivery concentrations minus enrollment concentrations) were both associated with a probability that $1000 \mathrm{mg}$ /day is better than $200 \mathrm{mg} /$ day ( $\mathrm{pp}=0.84$ and 0.99 , respectively) in modulating 
the expression of these molecules. There was a significantly smaller decrease in sRAGE for mothers receiving the higher-dose DHA supplement (1000 mg per day) compared to those receiving the lower-dose DHA supplement (200 mg per day, pp $=0.84$ ). The higher-dose DHA supplement group had a substantially larger increase in IL-6 from baseline to delivery compared to the lower-dose DHA supplement group ( $\mathrm{pp}=0.99$ ).

Table 4. Change in sRAGE/cytokine levels between enrollment and delivery, posterior means of the change (Bayesian credible intervals), and Bayesian posterior probability with treatment group (alone) as a predictor.

\begin{tabular}{|c|c|c|c|c|c|}
\hline & \multicolumn{2}{|c|}{$\begin{array}{l}\text { Observed Difference } \\
\text { (Delivery-Enrollment) }\end{array}$} & \multicolumn{2}{|c|}{$\begin{array}{c}\text { Posterior Mean } \\
\text { (95\% Bayesian Credible Interval) }\end{array}$} & \multirow[t]{2}{*}{$\begin{array}{l}\text { Bayesian Posterior } \\
\text { Probability (1000 mg Is } \\
\text { Greater than } 200 \mathrm{mg})\end{array}$} \\
\hline & $200 \mathrm{mg}$ & $1000 \mathrm{mg}$ & $200 \mathrm{mg}$ & $1000 \mathrm{mg}$ & \\
\hline $\begin{array}{l}\text { sRAGE } \\
{[\mathrm{pg} / \mathrm{mL}]}\end{array}$ & $\begin{array}{c}-96.76 \\
(244.43)\end{array}$ & $\begin{array}{c}-77.49 \\
(324.63)\end{array}$ & $\begin{array}{c}-96.94 \\
(-663.9,472.4)\end{array}$ & $\begin{array}{c}-77.55 \\
(-651.5,496.7)\end{array}$ & 0.84 \\
\hline $\begin{array}{c}\text { IL-6 } \\
{[\mathrm{pg} / \mathrm{mL}]}\end{array}$ & $\begin{array}{c}3.66 \\
(7.33)\end{array}$ & $\begin{array}{c}6.36 \\
(23.91)\end{array}$ & $\begin{array}{c}3.65 \\
(-31.60,39.08)\end{array}$ & $\begin{array}{c}6.36 \\
(-29.18,42.01)\end{array}$ & 0.99 \\
\hline IL-1 $\beta$ & 0.15 & 0.18 & 0.15 & 0.18 & \\
\hline$[\mathrm{pg} / \mathrm{mL}]$ & $(0.84)$ & $(1.05)$ & $(-1.73,2.03)$ & $(-1.72,2.08)$ & 0.70 \\
\hline $\mathrm{TNF} \alpha$ & 0.39 & 0.28 & 0.39 & 0.28 & \\
\hline [pg/mL] & $(0.71)$ & $(2.14)$ & $(-2.78,3.57)$ & $(-2.93,3.5)$ & 0.16 \\
\hline INF $\gamma$ & -1.32 & -0.66 & -1.34 & -0.67 & 0.64 \\
\hline$[\mathrm{pg} / \mathrm{mL}]$ & $(38.29)$ & (16.19) & $(-58.62,56.53)$ & $(-58.37,56.98)$ & 0.64 \\
\hline
\end{tabular}

At least 5000 burn-in and 40,000 Markov chain draws were performed.

\section{Discussion}

Modulation of the maternal immune system occurs during pregnancy to protect the fetus [23]. Inflammation is essential for the initiation of labor but has also been linked to an increased risk of developing pregnancy-related morbidities such as chorioamnionitis and preterm birth [1]. Studies in vitro associated DHA with the attenuation of transcription factor activities such as nuclear factor (NF)-kB, mitogen-activated protein (MAP) kinases, and transcriptional activation of the cytokines that are associated with inflammation, such as TNF $\alpha$, IL1, and IL-17 [24]. Understanding whether these mechanisms may contribute to the prevention of preterm birth associated with higher-dose DHA supplementation is therefore important to understand.

Leukocyte infiltration, cytokine release, and the resulting inflammation contribute to the initiation of parturition, and the maternal response to this inflammation provides protective effects for both mother and infant [1,2]. RAGE is a transmembrane receptor with distinct extra- and intra-cellular domains, and full-length RAGE is membrane bound and propagates signaling pathways regulating inflammation or immune responses [25]. Alternatively, RAGE exists in multiple extracellular isoforms (soluble RAGE or sRAGE) as a result of either alternative splicing or proteolytic cleavage [26-28]. For the purposes of this study, the specific forms of extracellular RAGE were not distinguished, and all extracellular and soluble RAGE was measured and referred to as SRAGE. sRAGE has been described with opposing functions: first, as a decoy receptor binding ligands and preventing intracellular signaling; and second, by binding CD11b on the surface of leukocytes, activating NFkB-mediated pathways, and propagating inflammation [25,29,30]. Consequently, the function of sRAGE depends upon the extracellular milieu and the severity of the inflammatory responses. While previous studies have reported differing findings, most have described sRAGE levels decreasing from early gestation to parturition, but substantially lower sRAGE levels were observed in mothers who experience spontaneous preterm delivery. On the contrary, inflammatory conditions that are associated with medically indicated preterm birth, such as preeclampsia, have generally led to higher sRAGE levels at delivery [31,32]. 
Several studies identified gradual increases in maternal serum sRAGE levels through the second trimester and then significant decreases approaching birth [33-36]. Others have speculated that the microinflammation and oxidative stress that occur during parturition create ligands for RAGE and sRAGE and that available sRAGE then acts as a decoy receptor to prevent deleterious responses. This would explain the decreases in SRAGE at birth and support the concept that higher levels early in gestation are protective [32].

Mothers who give birth prematurely ( $<37$ weeks) have lower levels of sRAGE than mothers who deliver at term $[21,32,36,37]$. This further decrease in sRAGE concentration is likely due to the events associated with the onset of preterm labor (or parturition) which are often associated with inflammation and similar inflammatory mediators that interact with available sRAGE. Several investigations have suggested that higher levels of sRAGE are associated with longer latency in the context of preterm birth [37], and Bastek et al. reported that lower maternal serum sRAGE levels were associated with a two-fold increase in the odds of preterm birth [38].

Our data are in line with previous reports that a higher baseline level of sRAGE offers protection against preterm birth, allowing for a buffer against pregnancy-related inflammatory responses. We observed that higher levels of sRAGE at enrollment were associated with a high probability of longer gestation and a greater probability of birth at term ( $\geq 37$ weeks) (Table 2$)$. However, in the context of morbidities such as preeclampsia and obesity, maternal inflammation occurs at a higher level throughout gestation, and sRAGE concentrations are increased to respond to this challenge. Thus, higher sRAGE levels at parturition are associated with a high probability of shorter gestational length and a greater probability of preterm birth (<37 weeks) (Table 2). Finally, smaller changes in sRAGE were associated with higher-dose DHA supplementation (1000 mg per day) compared to a standard lower dose (200 mg per day, Table 4) and a greater probability that higher-dose DHA supplementation is better than a lower dose in maintaining sRAGE levels during pregnancy. This data may be interpreted to mean that supplementing with $1000 \mathrm{mg}$ per day of DHA supports a more robust production of sRAGE and the capacity to reduce inflammation in pregnancy. An important limitation to note was there was more sRAGE (and cytokine) data missing for those born prematurely compared to the term births, as noted above in Section 3. Interesting future work could incorporate Bayesian methods using the other factors included in the models to conduct multiple imputation with the missing values.

Inflammatory responses due to paracrine interactions within the pregnant uterus are essential components in the initiation of labor. Elevations in IL- 6 , IL-1 $\beta$, and TNF $\alpha$ levels occur within the process of normal delivery at term, but levels are often more elevated in the context of pregnancy complications and preterm birth [39]. IL-6 is one of the most abundant and influential cytokines throughout gestation and plays a significant role in regulating the release of prostaglandins for parturition [1,39]. While IL-6 does not stimulate contractions, the onset of labor causes a 1.5-fold increase in IL-6 compared to non-pregnant women, but the increases are greater in the context of chorioamnionitis, infection, or preterm birth [1]. Furthermore, some epidemiological evidence links higher IL-6 levels to preterm birth and suggests that IL-6 levels may be a biomarker of early delivery [22]. In the current study, no association was observed between IL-6 levels at enrollment or delivery and gestational age at birth. However, the probability of giving birth after 37 weeks' gestation was associated with higher IL-6 levels (Table 3). As indicated in Table 4, the group treated with a higher-dose DHA supplement had a greater increase in IL-6 levels compared to those who received a lower-dose DHA supplement. One interpretation of these findings is that IL-6 plays a significant role in regulating the parturition process and that higher levels support uterine quiescence until term gestational age.

IL-1 $\beta$ is a significant regulator of inflammation and labor-inducing genes. It is a stimulator of COX-2 and thus prostaglandin synthesis and is an upstream inducer of IL-6 production $[20,22,40]$. IL-1 $\beta$ activates and regulates early responses to infection, activates $\mathrm{NF}-\mathrm{kB}$, and is associated with the onset of spontaneous preterm birth. Our analyses did 
not identify any significant differences in IL-1 $\beta$ and gestational age at birth, preterm birth ( $<37$ weeks), or the DHA treatment groups (Tables 3 and 4 ). TNF $\alpha$ is a proinflammatory cytokine that promotes protection from bacterial and viral infections but has also been associated with medical complications of pregnancy such as diabetes and preeclampsia $[20,22,40]$. Higher TNF $\alpha$ levels at delivery were associated with an increased probability of a shorter gestational length and a greater probability of preterm birth ( $<37$ weeks) (Table 3$)$. INF $\gamma$ acts as a chemoattractant and activates macrophages to facilitate host responses in the face of cellular pathogens. Higher INF $\gamma$ levels at delivery were associated with the probability of an earlier gestational age at birth $[20,22,39]$ (Table 3). Neither TNF $\alpha$ nor INF $\gamma$ were associated with the DHA supplement amount (high versus low dose). TNF $\alpha$ and INF $\gamma$ are not causally associated with the parturition process but are elevated with inflammatory conditions associated with pregnancy such as chorioamnionitis [40], exposure to environmental pollutants [41], preterm rupture of membranes [41], preeclampsia, gestational diabetes [22], and preterm birth [20].

\section{Conclusions}

In summary, our data indicate that higher baseline and lower delivery levels of maternal sRAGE are associated with a greater probability for longer gestation and delivery at term gestation. Furthermore, we found that higher-dose DHA supplementation increased the probability of a smaller decrease between sRAGE levels at enrollment and delivery. Higher IL-6 concentrations at delivery were also associated with the probability of delivering after 37 weeks and higher-dose DHA supplementation increased the probability of greater increases in IL-6 concentrations between enrollment and delivery. These data obtained from a prospective clinical trial provide a potential mechanistic explanation of how a higher-dose DHA supplement during pregnancy might provide immunomodulatory regulation of the initiation of parturition through its influence on sRAGE and IL-6 levels, which may explain its ability to reduce the risk of preterm birth. A prospective study to evaluate these relationships is needed.

Author Contributions: Conceptualization, C.J.V., E.A.D., B.J.G. and S.E.C.; Data curation, A.Q.K., S.A.S. and L.K.R.; Formal analysis, A.R.B. and B.J.G.; Funding acquisition, C.J.V., B.J.G., S.E.C., K.M.R. and L.K.R.; Methodology, A.Q.K., S.A.S., S.E.C. and L.K.R.; Project administration, C.J.V., B.J.G. and S.E.C.; Resources, S.A.S.; Supervision, L.K.R. and C.J.V.; Validation, A.R.B. and A.Q.K.; Writingoriginal draft, L.K.R.; Writing—review \& editing, A.Q.K., A.R.B., S.A.S., E.A.D., B.J.G., S.E.C., K.M.R. and L.K.R. All authors have read and agreed to the published version of the manuscript.

Funding: This research was funded by National Institutes of Health, Eunice Kennedy Shriver National Institute of Child and Health and Human Development, R01HD083292, and a grant from Nationwide Children's Hospital, 51139-0002-0320.

Institutional Review Board Statement: As a multicenter trial, women were recruited from three large academic medical centers, University of Kansas, Ohio State University, and University of Cincinnati. The study was conducted according to the guidelines of the Declaration of Helsinki and approved by The University of Kansas Medical Center IRB which granted approval under a central IRB with reliance by the other institutions (STUDY00003455). The study protocol is published (Carlson et al., 2017) [42]. The trial is registered (ClinicalTrials.gov: NCT02626299 accessed on 17 October 2021). Both the study protocol and statistical analysis plan are accessible at https://r2d2 .kumc.edu/ADORE/index.jsp, accessed on 17 October 2021.

Informed Consent Statement: Informed consent was obtained from all subjects involved in the study.

Data Availability Statement: The availability of deidentified data from this study is contingent on a signed data access agreement of the participants and the PIs and approval of the planned use of the data. A specific request made to S.E.C. (scarlson@kumc.edu) or B.J.G. (bgajewski@kumc.edu) is required to generate a data output for other investigators. 
Acknowledgments: We are grateful to the 1100 women who enrolled in the study. Additionally, we would like to acknowledge the support of numerous study personnel who recruited participants, communicated with them monthly, and collected the data critical for the study. The authors acknowledge support from NICHD R01HD083292 and Nationwide Children's Hospital during the duration of this study. At the time of the study, C.J.V. is an employee of RB Nutrition, however, RB was not involved in the study execution or analysis. Her role in this study was through her position as an Adjunct Professor at the University of Cincinnati.

Conflicts of Interest: The authors declare no conflict of interest.

\section{References}

1. Prairie, E.; Cote, F.; Tsakpinoglou, M.; Mina, M.; Quiniou, C.; Leimert, K.; Olson, D.; Chemtob, S. The determinant role of IL-6 in the establishment of inflammation leading to spontaneous preterm birth. Cytokine Growth Factor Rev. 2021, 59, 118-130. [CrossRef]

2. Romero, R.; Espinoza, J.; Kusanovic, J.P.; Gotsch, F.; Hassan, S.; Erez, O.; Chaiworapongsa, T.; Mazor, M. The preterm parturition syndrome. BJOG 2006, 113 (Suppl. 3), 17-42. [CrossRef]

3. Calder, P.C. Immunomodulation by omega-3 fatty acids. Prostaglandins Leukot Essent Fat. Acids 2007, 77, 327-335. [CrossRef]

4. Middleton, P.; Gomersall, J.C.; Gould, J.F.; Shepherd, E.; Olsen, S.F.; Makrides, M. Omega-3 fatty acid addition during pregnancy. Cochrane Database Syst. Rev. 2018, 11, CD003402. [CrossRef]

5. Valentine, C.J.; Dingess, K.A.; Kleiman, J.; Morrow, A.L.; Rogers, L.K. A Randomized Trial of Maternal Docosahexaenoic Acid Supplementation to Reduce Inflammation in Extremely Preterm Infants. J. Pediatr. Gastroenterol. Nutr. 2019, 69, 388-392. [CrossRef]

6. Yavin, E. Versatile roles of docosahexaenoic acid in the prenatal brain: From pro- and anti-oxidant features to regulation of gene expression. Prostaglandins Leukot Essent Fat. Acids 2006, 75, 203-211. [CrossRef]

7. Calder, P.C. The relationship between the fatty acid composition of immune cells and their function. Prostaglandins Leukot Essent Fat. Acids 2008, 79, 101-108. [CrossRef]

8. Himmelfarb, J.; Phinney, S.; Ikizler, T.A.; Kane, J.; McMonagle, E.; Miller, G. Gamma-tocopherol and docosahexaenoic acid decrease inflammation in dialysis patients. J. Ren. Nutr. 2007, 17, 296-304. [CrossRef]

9. Simopoulos, A.P. Omega-3 fatty acids in inflammation and autoimmune diseases. J. Am. Coll. Nutr. 2002, 21, 495-505. [CrossRef]

10. McCann, J.C.; Ames, B.N. Is docosahexaenoic acid, an n-3 long-chain polyunsaturated fatty acid, required for development of normal brain function? An overview of evidence from cognitive and behavioral tests in humans and animals. Am. J. Clin. Nutr. 2005, 82, 281-295. [CrossRef]

11. Rizza, S.; Tesauro, M.; Cardillo, C.; Galli, A.; Iantorno, M.; Gigli, F.; Sbraccia, P.; Federici, M.; Quon, M.J.; Lauro, D. Fish oil supplementation improves endothelial function in normoglycemic offspring of patients with type 2 diabetes. Atherosclerosis 2009, 206, 569-574. [CrossRef]

12. Calder, P.C. The role of marine omega-3 (n-3) fatty acids in inflammatory processes, atherosclerosis and plaque stability. Mol. Nutr. Food Res. 2012, 56, 1073-1080. [CrossRef]

13. Rogers, L.K.; Graf, A.E.; Bhatia, A.; Leonhart, K.L.; Oza-Frank, R. Associations between maternal and infant morbidities and sRAGE within the first week of life in extremely preterm infants. PLoS ONE 2013, 8, e82537. [CrossRef]

14. Rogers, L.K.; Valentine, C.J.; Keim, S.A. DHA supplementation: Current implications in pregnancy and childhood. Pharmacol. Res. 2013, 70, 13-19. [CrossRef]

15. Matesanz, N.; Park, G.; McAllister, H.; Leahey, W.; Devine, A.; McVeigh, G.E.; Gardiner, T.A.; McDonald, D.M. Docosahexaenoic acid improves the nitroso-redox balance and reduces VEGF-mediated angiogenic signaling in microvascular endothelial cells. Investig. Ophthalmol. Vis. Sci. 2010, 51, 6815-6825. [CrossRef]

16. Kar, S.; Wong, M.; Rogozinska, E.; Thangaratinam, S. Effects of omega-3 fatty acids in prevention of early preterm delivery: A systematic review and meta-analysis of randomized studies. Eur. J. Obstet. Gynecol. Reprod. Biol. 2016, 198, 40-46. [CrossRef]

17. Carlson, S.E.; Colombo, J.; Gajewski, B.J.; Gustafson, K.M.; Mundy, D.; Yeast, J.; Georgieff, M.K.; Markley, L.A.; Kerling, E.H.; Shaddy, D.J. DHA supplementation and pregnancy outcomes. Am. J. Clin. Nutr. 2013, 97, 808-815. [CrossRef]

18. Koletzko, B.; Cetin, I.; Brenna, J.T. Dietary fat intakes for pregnant and lactating women. Br. J. Nutr. 2007, 98, 873-877. [CrossRef]

19. Carlson, S.E.; Gajewski, B.J.; Valentine, C.J.; Kerling, E.H.; Weiner, C.P.; Cackovic, M.; Buhimschi, C.S.; Rogers, L.K.; Sands, S.A.; Brown, A.R.; et al. Higher dose docosahexaenoic acid supplementation during pregnancy and early preterm birth: A randomised, double-blind, adaptive-design superiority trial. EClinicalMedicine 2021, 36, 100905. [CrossRef]

20. Kalagiri, R.R.; Carder, T.; Choudhury, S.; Vora, N.; Ballard, A.R.; Govande, V.; Drever, N.; Beeram, M.R.; Uddin, M.N. Inflammation in Complicated Pregnancy and Its Outcome. Am. J. Perinatol. 2016, 33, 1337-1356. [CrossRef]

21. Germanova, A.; Koucky, M.; Hajek, Z.; Parizek, A.; Zima, T.; Kalousova, M. Soluble receptor for advanced glycation end products in physiological and pathological pregnancy. Clin. Biochem. 2010, 43, 442-446. [CrossRef]

22. Chau, A.; Markley, J.C.; Juang, J.; Tsen, L.C. Cytokines in the perinatal period-Part II. Int. J. Obstet. Anesth. 2016, 26, 48-58. [CrossRef]

23. Abu-Raya, B.; Michalski, C.; Sadarangani, M.; Lavoie, P.M. Maternal Immunological Adaptation During Normal Pregnancy. Front. Immunol. 2020, 11, 575197. [CrossRef] 
24. Allam-Ndoul, B.; Guenard, F.; Barbier, O.; Vohl, M.C. Effect of n-3 fatty acids on the expression of inflammatory genes in THP-1 macrophages. Lipids Health Dis. 2016, 15, 69. [CrossRef]

25. Chavakis, T.; Bierhaus, A.; Al-Fakhri, N.; Schneider, D.; Witte, S.; Linn, T.; Nagashima, M.; Morser, J.; Arnold, B.; Preissner, K.T.; et al. The pattern recognition receptor (RAGE) is a counterreceptor for leukocyte integrins: A novel pathway for inflammatory cell recruitment. J. Exp. Med. 2003, 198, 1507-1515. [CrossRef]

26. Buckley, S.T.; Ehrhardt, C. The receptor for advanced glycation end products (RAGE) and the lung. J. Biomed. Biotechnol. 2010, 2010, 917108. [CrossRef]

27. Morbini, P.; Villa, C.; Campo, I.; Zorzetto, M.; Inghilleri, S.; Luisetti, M. The receptor for advanced glycation end products and its ligands: A new inflammatory pathway in lung disease? Mod. Pathol. 2006, 19, 1437-1445. [CrossRef]

28. Schlueter, C.; Hauke, S.; Flohr, A.M.; Rogalla, P.; Bullerdiek, J. Tissue-specific expression patterns of the RAGE receptor and its soluble forms-a result of regulated alternative splicing? Biochim. Biophys. Acta 2003, 1630, 1-6. [CrossRef]

29. Wang, Y.; Wang, H.; Piper, M.G.; McMaken, S.; Mo, X.; Opalek, J.; Schmidt, A.M.; Marsh, C.B. sRAGE induces human monocyte survival and differentiation. J. Immunol. 2010, 185, 1822-1835. [CrossRef]

30. Raucci, A.; Cugusi, S.; Antonelli, A.; Barabino, S.M.; Monti, L.; Bierhaus, A.; Reiss, K.; Saftig, P.; Bianchi, M.E. A soluble form of the receptor for advanced glycation endproducts (RAGE) is produced by proteolytic cleavage of the membrane-bound form by the sheddase a disintegrin and metalloprotease 10 (ADAM10). FASEB J. 2008, 22, 3716-3727. [CrossRef]

31. Oliver, E.A.; Buhimschi, C.S.; Dulay, A.T.; Baumbusch, M.A.; Abdel-Razeq, S.S.; Lee, S.Y.; Zhao, G.; Jing, S.; Pettker, C.M.; Buhimschi, I.A. Activation of the receptor for advanced glycation end products system in women with severe preeclampsia. J. Clin. Endocrinol. Metab. 2011, 96, 689-698. [CrossRef]

32. Hajek, Z.; Germanova, A.; Koucky, M.; Zima, T.; Kopecky, P.; Vitkova, M.; Parizek, A.; Kalousova, M. Detection of feto-maternal infection/inflammation by the soluble receptor for advanced glycation end products (sRAGE): Results of a pilot study. J. Perinat. Med. 2008, 36, 399-404. [CrossRef]

33. Kwon, J.H.; Kim, Y.H.; Kwon, J.Y.; Park, Y.W. Clinical significance of serum sRAGE and esRAGE in women with normal pregnancy and preeclampsia. J. Perinat. Med. 2011, 39, 507-513. [CrossRef]

34. Chen, W.; Zhang, Y.; Yue, C.; Ye, Y.; Chen, P.; Peng, W.; Wang, Y. Accumulation of Advanced Glycation End Products Involved in Inflammation and Contributing to Severe Preeclampsia, in Maternal Blood, Umbilical Blood and Placental Tissues. Gynecol. Obstet. Investig. 2017, 82, 388-397. [CrossRef]

35. Quintanilla-Garcia, C.V.; Uribarri, J.; Fajardo-Araujo, M.E.; Barrientos-Romero, J.J.; Romero-Gutierrez, G.; Reynaga-Ornelas, M.G.; Garay-Sevilla, M.E. Changes in circulating levels of carboxymethyllysine, soluble receptor for advanced glycation end products (sRAGE), and inflammation markers in women during normal pregnancy. J. Matern. Fet. Neonat. Med. 2019, 32, $4102-4107$. [CrossRef]

36. Rzepka, R.; Dolegowska, B.; Rajewska, A.; Salata, D.; Budkowska, M.; Kwiatkowski, S.; Torbe, A. Diagnostic Potential of Evaluation of SDF-1alpha and sRAGE Levels in Threatened Premature Labor. Biomed. Res. Int. 2016, 2016, 2719460. [CrossRef]

37. Rzepka, R.; Dolegowska, B.; Rajewska, A.; Kwiatkowski, S.; Salata, D.; Budkowska, M.; Domanski, L.; Mikolajek-Bedner, W.; Torbe, A. Soluble and Endogenous Secretory Receptors for Advanced Glycation End Products in Threatened Preterm Labor and Preterm Premature Rupture of Fetal Membranes. Biomed. Res. Int. 2015, 2015, 568042. [CrossRef]

38. Bastek, J.A.; Brown, A.G.; Foreman, M.N.; McShea, M.A.; Anglim, L.M.; Adamczak, J.E.; Elovitz, M.A. The soluble receptor for advanced glycation end products can prospectively identify patients at greatest risk for preterm birth. J. Matern. Fet. Neonat. Med. 2012, 25, 1762-1768. [CrossRef]

39. Leimert, K.B.; Xu, W.; Princ, M.M.; Chemtob, S.; Olson, D.M. Inflammatory Amplification: A Central Tenet of Uterine Transition for Labor. Front. Cell. Infect. Microbiol. 2021, 11, 660983. [CrossRef]

40. Ren, J.; Qiang, Z.; Li, Y.Y.; Zhang, J.N. Biomarkers for a histological chorioamnionitis diagnosis in pregnant women with or without group B streptococcus infection: A case-control study. BMC Pregnancy Childbirth 2021, 21, 250. [CrossRef]

41. Li, W.; Zhao, X.; Li, S.; Chen, X.; Cui, H.; Chang, Y.; Zhang, R. Upregulation of TNF-alpha and IL-6 induces preterm premature rupture of membranes by activation of ADAMTS-9 in embryonic membrane cells. Life Sci. 2020, 260, 118237. [CrossRef]

42. Carlson, S.E.; Gajewski, B.J.; Valentine, C.J.; Rogers, L.K.; Weiner, C.P.; DeFranco, E.A.; Buhimschi, C.S. Assessment of DHA on reducing early preterm birth: The ADORE randomized controlled trial protocol. BMC Pregnancy Childbirth 2017, 17, 62. [CrossRef] [PubMed] 